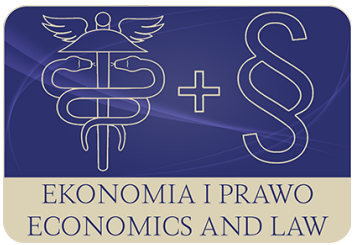

EKONOMIA I PRAWO. ECONOMICS AND LAW

Volume 19, Issue 2, June 2020

p-ISSN 1898-2255, e-ISSN 2392-1625

www.economicsandlaw.pl

EKONOMIA I PRAWO
ECONOMICS AND LAW

ORIGINAL ARTICLE

received 16.03.2020; revised 22.05.2020; accepted 30.06.2020

Citation: Topolewski, Ł. (2020). The impact of income inequalities on economic growth. Ekonomia

iPrawo. Economics and Law, 19(2): 355-365. doi:10.12775/EiP.2020.024.

\title{
The impact of income inequalities on economic growth
}

\author{
EUKASZ TOPOLEWSKI \\ Nicolaus Copernicus University in Toruń, Faculty of Economic Sciences and Management, \\ Department of Economics, ul. Gagarina 13a, 87-100 Toruń, Poland \\ ๑ lukasz.topolewski@umk.pl \\ (D) orcid.org/0000-0002-1548-4816
}

\begin{abstract}
Motivation: The problem of income inequalities is a growing one, worldwide. Therefore, it should be investigated how this phenomenon affects the prospects of productivity increase in a particular economy. The answer to this problem will also decide whether the reduction of income inequalities in a society ought to be the main focus of instituted economic policies.

Aim: The purpose of the article is to determine the character of the relationship between income inequality and economic growth, and decide whether income inequalities have a positive or negative impact on economic growth. To this end, a theoretical analysis and review of existing research were conducted. Afterwards, an attempt to verify the above-mentioned relationship empirically with the use of dynamic panel models was made. The period covered by the study is 2001-2018. Data were obtained from Eurostat and World Bank databases.

Results: The study found that there was a statistically significant, negative relationship between income inequalities (measured by the Gini coefficient) and economic growth in the sample group. The results of this study do not differ from the results of other authors who verified the above relationship for other sample groups.
\end{abstract}

Keywords: income inequalities, economic growth, dynamic panel models JEL: D63; O15; O40 


\section{Introduction}

The problem of income inequalities is a growing one, worldwide. Therefore, it should be investigated how this phenomenon affects the prospects of productivity increase in a particular economy. The answer to this problem will also decide whether the reduction of income inequalities in a society ought to be the main focus of instituted economic policies.

From the perspective of economic theory, income inequalities are seen as income disparities between the poor and the rich. These disproportions may also be related to wealth, education, employment or life satisfaction. Since the end of World War II, many economies have undergone rapid economic growth. However, the increase of production has been accompanied by an uneven distribution of acquired wealth. This resulted in some social groups obtaining wealth faster than other ones (Andrei \& Crăciun, 2015, pp. 177-178). A point to consider then is whether this uneven distribution of wealth will be conducive to further production growth or have a detrimental effect on productivity. Perhaps governments of individual economies could shape their economic policies in a way that would make reducing these income inequalities possible. One of the first researchers to undertake research on the relationship between income inequality and economic growth was Kuznets (1955).

The purpose of the article is to determine the character of the relationship between income inequality and economic growth, and decide whether income inequalities have a positive or negative impact on economic growth. To this end, a theoretical analysis and review of existing research were conducted. Afterwards, an attempt to verify the above-mentioned relationship empirically with the use of dynamic panel models was made. The period covered by the study is 2001-2018. Data were obtained from Eurostat (2020) and World Bank (2020) databases.

\section{Literature review}

Barro (2000, pp. 5-6) divided the theories describing the relationship between income inequalities and economic growth into four categories that refer to: flaws of a credit market, political economy, social unrest and the savings rate.

Credit market flaws are related to information asymmetry and limitations of legal institutions. The creditors may have difficulties with recovering their unpaid loans, and the law can protect the debtor's assets. As a result, credit availability becomes limited. Therefore, entities that do not have their own funds or assets cannot obtain funds on the financial market. The inability to raise funds prevents making any substantial investments in the development of your skills and knowledge. People could have high rates of return on investment in human capital, but they cannot achieve them due to the lack of financial resources. People with low income and no assets are unable to improve their situation at all. Consequently, their income varies more and more from the income of wealthy 
people, who can make investments in human capital. This allows them to increase their income and achieve higher rates of return on investment in human capital. The lack of investment in human capital by poor people means that the economy does not grow at the pace it could reasonably achieve (Galor \& Zeira, 1993, pp. 37-43).

Political economy is another channel through which income inequalities can affect the economic situation. If a given economy is characterized by significant income inequalities, then the citizens may assert pressure on the government in order to make the economic policies eliminate income disparities. In response to these needs, the government may introduce transfer payments to the poorer citizens, or may expand public spending programs targeted at education or healthcare. Redistribution programs require obtaining additional funds, which forces the increase in tax rates or even the introduction of new taxes. As a result, this increase in tax burden distorts business decisions and reduces people's desire to make work-related efforts. Thus, there is no motivation to increase investment, which translates into lower dynamics of production growth. Higher inequalities also affect the behaviour of wealthy groups, as they try to put pressure on those in power to give their social group preferential treatment. These are conditions for over-investment in selected areas of an economy or an increase in corruption (Lee \& Son, 2016, pp. 331-333).

Another consequence of large income disparities is the possibility of reduced political stability. Less wealthy people may commit criminal, destructive acts. This reduces their involvement in productive activities, and affects the decisions of other people, because they might put the undertakings of wealthy people at risk. Consequently, investments decrease. Such behaviour also affects potential foreign investment, as it may have a negative impact on investment plans (Alesina \& Perotti, 1996, pp. 1203-1206).

The relationship between income inequalities and economic growth can also be explained using the savings rate. The greater the income disparities, the greater the savings in the economy. It is assumed, according to the Keynesian approach, that the savings rate depends on the income obtained. Thus, the desire to equalize income levels can have a negative impact on savings rates, and hence on domestic investment. In short, the higher the income inequality and the higher savings rates, the greater the investments and the higher the economic growth rates (Barro, 2000, p. 8).

The issue of income inequality and economic growth was the subject of research of many economists in the 1990s. This relationship was analysed by Alesina \& Rodrik (1994, pp. 478-485), among others. They analysed a sample group of 70 economies operating in the period of 1960-1985. The sample group included mainly developing countries. The authors of this study observed a negative and statistically significant correlation between income inequality (measured by the Gini coefficient) and economic growth. The test method used by Alesina \& Rodrik (1994, pp. 478-485), as well as other cited authors, will be described later in the article. Similar studies were carried out by Persson \& Ta- 
bellini (1994, pp. 610-618). They researched a sample group of 56 economies in the same period, i.e. 1960-1985. They came to the same conclusions, namely that income inequalities negatively affect economic growth in a statistically significant way. Deininger \& Squire (1998, pp. 275-287) analysed 87 countries from the period of 1960-1992. They came to a similar conclusion in their research - the analysed relationship is negative, which means that the higher the income inequality, the lower the economic growth rates. It should be emphasized that the parameter next to the variable denoting income inequality was not statistically significant.

It is worth taking into consideration the results of the research presented by $\mathrm{Li}$ \& Zou (1998), because the conclusions presented in their study differed significantly from those presented so far. They analysed 46 economies from the period of 1947-1994. They had to average their observations because they had faced the problem of insufficient data, which resulted in an unbalanced panel data. Li \& Zou (1998, pp. 321-325) discovered that the relationship between income inequality and economic growth was positive and statistically significant. Forbes (2000, pp. 874-878) confirms this direction of the impact of income inequality on economic growth. In her study, she analysed the relationship in the period of 1966-1995. Similarly to Li \& Zou (1998), she averaged the values of the studied variables over a 5 -year period, which limited the number of observations in time to six. The analysis was conducted on a sample group of 45 countries. Forbes (2000, pp. 874-878) estimated the parameters using various methods, but in each of them, the parameter evaluation indicated a positive relationship between income inequalities and economic growth.

Castelló-Climent (2010, pp. 301-315) obtained different results, with an extended time range of the study to a period of 1960-2000. The subjective scope was different as well, as she analysed as many as 102 economies. An additional advantage of this study is taking into consideration economies at various levels of development. This approach allowed the author to analyse the relationship between income inequalities and economic growth in relation to the level of wealth. The analysis of the full sample and the assessment of the parameter under Gini coefficient indicated a negative and statistically significant relationship between income inequalities and economic growth. The same kinds of impact were verified for low and medium developed economies. However, in the case of developed economies, income inequalities do not constitute an obstacle to production growth. Ostry et al. (2014, pp. 15-24) extended the time range even more, thus analysing the period of 1960-2010. The subject scope of the study covered 90 economies. The conclusions of the study suggest that inequalities have a negative impact on economic growth. Another set of interesting studies was carried out by Lee \& Son (2016). The scope of this study covered 107 economies in the period of 1960-2010. According to the conclusions of this study, income inequality has a negative impact on economic growth. The authors compared the obtained results with the results obtained by Forbes (2000). Trying to explain the differences, they formed three arguments. In the first one, 
they referred to the diversity of the analysed periods. Forbes (2000) studied the relationship in the period of 1965-1990, while D. J. Lee \& Son (2016) took on the period of 1965-2010, when the inequalities were on a significant rise, worldwide. The second argument concerned the subjective scope - Forbes (2000) analysed only 45 economies, most of which belong to the OECD, while Lee \& Son (2016) took into account as many as 107 economies. It should be noted that the latter group was more diversified, and included emerging economies as well as sub-Saharan African countries. They described the last possible source of discrepancies to be the estimation methods used in these studies. However, this argument will be discussed in more detail in the next part of the article.

The same considerations were presented by Voitchovsky (2005). She analyzed 21 countries from the period 1975-2000. She used system GMM techniques in a dynamic panel analysis. She came to the similar conclusion in her research - relationships between income inequality and economic growth is negative. She showed that impact direction can be different and it depends on level of wealth.

Hailemariam \& Dzhumashev (2019) suggested that income inequality has a nonlinear relationship with economic growth. When countries are poor income inequalities influence economic growth in positive way, otherwise the relationship is negative. Brueckner \& Lederman (2018) came to the same conclusions.

Atems \& Jones (2015) used an another method of research — a panel VAR approach. Their considerations showed, that income inequalities influence economic growth in negative way.

\section{Methods}

The research results cited in the previous section prove that the estimation method significantly alters the results obtained. In the 1990s, the OLS method was used in the research (e.g. Alesina \& Rodrik, 1994; Deininger \& Squire, 1998);Persson \& Tabellini, 1994), which resulted in the relationship being perceived as negative. This approach does not take into account the differences between countries; all of them are assumed to be the same. Forbes (2000) and Li \& Zou (1998) obtained similar results even though they used different estimation methods. They used an estimator of fixed effects and an estimator of the first differences. In one of the estimates, Lee \& Son (2016) used the data set proposed by Forbes (2000) and estimated parameters in accordance with the Blundell \& Bond (1998) approach, but the characteristics of the impact did not change. However, when they extended this data set with more years and estimated parameters according to two different estimators, Arellano \& Bond (1991) and Blundell \& Bond (1998) obtained different results. The constant effects estimator may give incorrect parameter estimates due to the delayed dependent variable, as this correlates the delayed dependent variable with a random component. 
As Castelló-Climent (2010, p. 295) claims, in the case of examining the discussed relationship, the Blundell \& Bond (1998, pp. 134-138) estimator ought to be used, as the economic growth process is characterized by relative stability, which means that the Arellano \& Bond (1991) estimator is not the right tool for verification.

In order to achieve the hypotheses proposed in the article the following equation was used:

$$
G N I_{i, t}=\alpha_{i}+\beta_{1} \cdot G N I_{i, t-1}+\beta_{2} \cdot G I N I_{i, t}+\beta_{3} \cdot X_{i, t}+\delta_{t}+\varepsilon_{i, t},
$$

where $i$ denotes the country and $t$ the year;

$G_{i, t}$ - Gross National Product per capita in country $i$ and year $t$ (at 2011 constant prices);

GINI $_{i, t}$ - income inequality measured by GINI in country $i$ and year $t$;

$X_{i, t}$ - variables control in country $i$ and year $t$;

$\alpha_{i}$ - individual effects;

$\delta_{t}$ - time specific-effects;

$\varepsilon_{t}$ - error term.

The introduction of a delayed dependent variable in the above model means that the estimation possibilities are much smaller. In this case, estimates based on the GMM method are usually chosen. In addition, an assumption is made about the relationship between the independent variables and the random component. The use of the Blundell \& Bond (1998) estimator requires estimation of equations at both increments and levels. In this way, while estimating the equation at levels, the delayed first differences of the explanatory variable become the instruments for this variable (Baltagi, 2005, pp. 147-148).

The article uses the Gini coefficient as a measure of income inequality. Statistical data were obtained from EU SILC, other data were obtained from the World Bank (2020) database. All data were expressed as three-year averages. In addition, all variables were logarithmed. The dependent variable was derived from the national income expressed in constant prices from 2011. The control variables included: school enrolment rate for females, school enrolment rate for males, government expenditures and gross capital formation. Control variables were selected based on a review of literature. The study was conducted on a sample group of 32 European countries. The time range of the survey covered the period of 2001-2018.

\section{Results}

Chart 1 presents the relationship between the level of income inequalities measured by the Gini coefficient and the Gross National Product per capita in the period of 2001-2018. It is difficult to see the relationship in this particular case, but based on the presented sample, the increase in per capita income resulted in a decrease in income inequality, followed by a slight increase. 
Table 1 presents the results of model estimations. For comparison, estimates are presented with the use of both the Arellano \& Bond (1991) estimators, as well as Blundell \& Bond (1998) estimators. Both estimators are presented in both one-stage and two-stage approaches. Initially, models were estimated by means of OLS and a fixed effects estimator. In this way, the parameter evaluation range for the delayed dependent variable for the first-difference estimator was determined. The evaluation of the standing parameter with the delayed dependent variable should be in the range of 0.7975-0.9136. Initially, parameters were estimated with the use of a single-stage estimator of first differences. Diagnostic tests indicated that the instruments used were appropriate. However, the parameter rating with a delayed dependent variable turned out to be too high. The use of a two-stage estimator did not bring significant improvement, either. The parameter rating was still too high. Because of this, one can confirm the conclusion of Castelló-Climent (2010) that the estimator of the first differences is not appropriate for estimating economic growth models. Next, parameter estimates were established using a Blundell \& Bond (1998) estimator. The results in table 1 confirmed that the parameter rating had decreased. In addition, the standard error had significantly decreased as well. Based on the second-order Arellano-Bond test, it was found that there were no grounds for rejecting the null hypothesis, which indicates the lack of autocorrelation of the random component. The next step was a Hansen's test. A p value of 0.14 suggested that there were no grounds to reject the null hypothesis. The instruments used had therefore been appropriate. Model diagnostics indicated that inferences could be made based on this estimate. It can be stated that the increase in inequality has a negative impact on economic growth. An estimation was also made using a two-stage estimator. The model was diagnosed in a similar way. Based on the $p$ value in the $\mathrm{AR}(2)$ test, it was decided that there were no grounds for rejecting the null hypothesis, which indicates the lack of autocorrelation of the random component. The p-value in Hansen's test took the value of 0.142 , which also suggests no grounds for rejecting the null hypothesis. It might be concluded that the instruments used were appropriate. In addition, a Hansen difference test was carried out. In this case, there were also no grounds to reject the null hypothesis. When assessing estimates using the Blundell \& Bond (1998) estimators, it was found that the two-stage estimator gave better results. Therefore, inferences were made based on the last estimation. Because of this, it can be concluded that the increase in income inequality has a negative impact on economic growth, because the parameter next to this variable is statistically significant. In addition to inequalities, capital accumulation has a statistically significant impact on economic growth. The character of this relationship is positive.

It is worth noting one more aspect. Table 1 includes the parameter evaluations with the use of Arellano \& Bond (1991) estimator. If conclusions were inferred from these estimates, one could claim that income inequality has a positive effect on economic growth. However, the variables are not statistically sig- 
nificant, but the parameter value is positive. This statement correlates directly to the considerations presented by Lee \& Son (2016).

\section{Conclusion}

On the basis of the study, it may be concluded that income inequality has a statistically significant impact on economic growth. The increase in income inequality has a negative impact on economic growth. The results of these studies do not differ significantly from the results presented by Castelló-Climent (2010) and Lee \& Son (2016) and others authors, that were cited. The character of the impact presented in the cited studies were similar. Therefore, governments should try to reduce income inequalities, because it may cause low economic growth. In the future, it would be worth extending the research for countries with varying levels of wealth. However, there is a problem with the availability of reliable and comparable data. The above-mentioned authors also mentioned this problem.

\section{References}

Alesina, A., \& Perotti, R. (1996). Income distribution, political instability, and investment. European Economic Review, 40(6). doi:10.1016/0014-2921(95)00030-5.

Alesina, A., \& Rodrik, D. (1994). Distributive politics and economic growth. The Quarterly Journal of Economics, 109(2). doi:10.2307/2118470.

Andrei, A., \& Crăciun, L. (2015). Inequality and economic growth: theoretical and operational approach. Theoretical and Applied Economics, 22(602).

Arellano, M., \& Bond, S. (1991). Some tests of specification for panel data: Monte Carlo evidence and an application to employment equations. The Review of Economic Studies, 58(2). doi:10.2307/2297968.

Atems, B., \& Jones, J. (2015). Income inequality and economic growth: a panel VAR approach. Empirical Economics, 48(4). doi:10.1007/s00181-014-0841-7.

Baltagi, B.H. (2005). Econometric analysis of panel data. Chichester: John Wiley $\&$ Sons.

Barro, R.J. (2000). Inequality and growth in a panel of countries. Journal of Economic Growth, 5(1). doi:10.1023/A:1009850119329.

Blundell, R., \& Bond, O. (1998). Initial conditions and moment restrictions in dynamic panel data models. Journal of Econometrics, 87(1). doi:10.1016/ s0304-4076(98)00009-8.

Brueckner, M., \& Lederman, D. (2018). Inequality and economic growth: the role of initial income. Journal of Economic Growth, 23(3). doi:10.1007/ sl0887-018-9156-4.

Castelló-Climent, A. (2010). Inequality and growth in advanced economies: an empirical investigation. Journal of Economic Inequality, 8(3). doi:10.1007/ s10888-010-9133-4. 
Deininger, K., \& Squire, L. (1998). New ways of looking at old issues: inequality and growth. Journal of Development Economics, 57(2). doi:10.1016/ s0304-3878(98)00099-6.

Eurostat. (2020). Retrieved 20.02.2020 from https://ec.europa.eu.

Forbes, K.J. (2000). A reassessment of the relationship between inequality and growth. American Economic Review, 90(4). doi:10.1257/aer.90.4.869.

Galor, O., \& Zeira, J. (1993). Income distribution and macroeconomics. The Review of Economic Studies, 60(1). doi:10.2307/2297811.

Hailemariam, A., \& Dzhumashev, R. (2019). Income inequality and economic growth: heterogeneity and nonlinearity. Studies in Nonlinear Dynamics \& Econometrics. Advance online publication. doi:10.1515/snde-2018-0084.

Kuznets, S. (1955). Economic growth and income inequality. The American Economic Review, 45(1).

Lee, D.J., \& Son, J.C. (2016). Economic growth and income inequality: evidence from dynamic panel investigation. Global Economic Review, 45(4). doi: 10.1080/1226508x.2016.1181980.

Li, H., \& Zou, H. (1998). Income inequality is not harmful for growth: theory and evidence. Review of Development Economics, 2(3). doi:10.1111/1467-9361.00045.

Ostry, J.D., Berg, A., \& Tsangarides, C.G. (2014). Redistribution, inequality, and growth. IMF Staff Discussion Note, SDN/14/02.

Persson, T., \& Tabellini, G. (1994). Is inequality harmful for growth. The American Economic Review, 84(3).

Voitchovsky, S. (2005). Does the profile of income inequality matter for economic growth: distinguishing between the effects of inequality in different parts of the income distribution. Journal of Economic Growth, 10(3). doi:10.1007/s10887-005-3535-3.

World Bank. (2020). Retrieved 20.02.2020 from https://data.worldbank.org.

\section{Acknowledgements}

Author contributions: author has given an approval to the final version of the article.

Funding: this research was funded by the Nicolaus Copernicus University in Torun, Faculty of Economic Sciences and Management statutory sources. 


\section{Appendix}

Table 1.

Estimation results using data from 2001 to 2018

\begin{tabular}{|c|c|c|c|c|}
\hline Variable dependent: $G N I_{i, t-l}$ & FDGMMl & FDGMM2 & SGMMl & SGMM2 \\
\hline \multirow{2}{*}{$G N I_{i, t-1}$} & 1.0209 & 1.0285 & 0.9035 & 0.8931 \\
\hline & $(0.0957)$ & $(0.0990)$ & $(0.0213)$ & $(0.0172)$ \\
\hline \multirow{2}{*}{$G I N I_{i, t}$} & 0.0581 & 0.1303 & -0.0494 & -0.0829 \\
\hline & $(0.1478)$ & $(0.1183)$ & $(0.0473)$ & $(0.0388)$ \\
\hline \multirow{2}{*}{$E D U \_M_{i, t}$} & -0.1270 & -0.1152 & 0.0207 & -0.0455 \\
\hline & $(0.0542)$ & $(0.0457)$ & $(0.0397)$ & $(0.0389)$ \\
\hline \multirow{2}{*}{$E D U_{-} F_{i, t}$} & -0.2177 & -0.2816 & 0.0704 & 0.0478 \\
\hline & $(0.2636)$ & $(0.1231)$ & $(0.1354)$ & $(0.1805)$ \\
\hline \multirow{2}{*}{$\operatorname{EXP}_{i, t}$} & -0.1434 & -0.1233 & -0.0383 & -0.0392 \\
\hline & $(0.1771)$ & $(0.1720)$ & $(0.0353)$ & $(0.0493)$ \\
\hline \multirow{2}{*}{$G C F_{i, t}$} & 0.2201 & 0.1821 & 0.1563 & 0.1402 \\
\hline & $(0.0715)$ & $(0.0508)$ & $(0.0260)$ & $(0.0333)$ \\
\hline number of observations & 100 & 100 & 131 & 131 \\
\hline number of countries & 30 & 30 & 30 & 30 \\
\hline Arellano-Bond test for AR(2) in differences (p-value) & 0.31 & 0.19 & 0.13 & 0.13 \\
\hline \multirow{2}{*}{$\begin{array}{l}\text { Hansen test of join validity of instruments (p-value) } \\
\text { difference-in-Hansen test ( } p \text {-value) }\end{array}$} & 0.486 & 0.486 & 0.142 & 0.142 \\
\hline & - & - & 0.772 & 0.772 \\
\hline number of instruments & 18 & 18 & 23 & 23 \\
\hline
\end{tabular}

Notes:

All models content dummy variables of time. Standard errors are in parentheses.

FDGMM1 - estimator one step difference GMM; FDGMM2 - estimator two step difference GMM; SGMM1 — estimator one step system GMM; SGMM2 - estimator two step system GMM; GNI — Gross National Product per capita; GINI — income inequality measured by GINI coefficient; $E D U_{-} F$ - school enrolment rate for females; EDU_M - school enrolment rate for males; GCF — gross capital formation.

Source: Own preparation. 
Chart 1.

Relationships between Gini coefficient and Gross National Product per capita (in thousands dollars) in 2001-2018 (n=172)

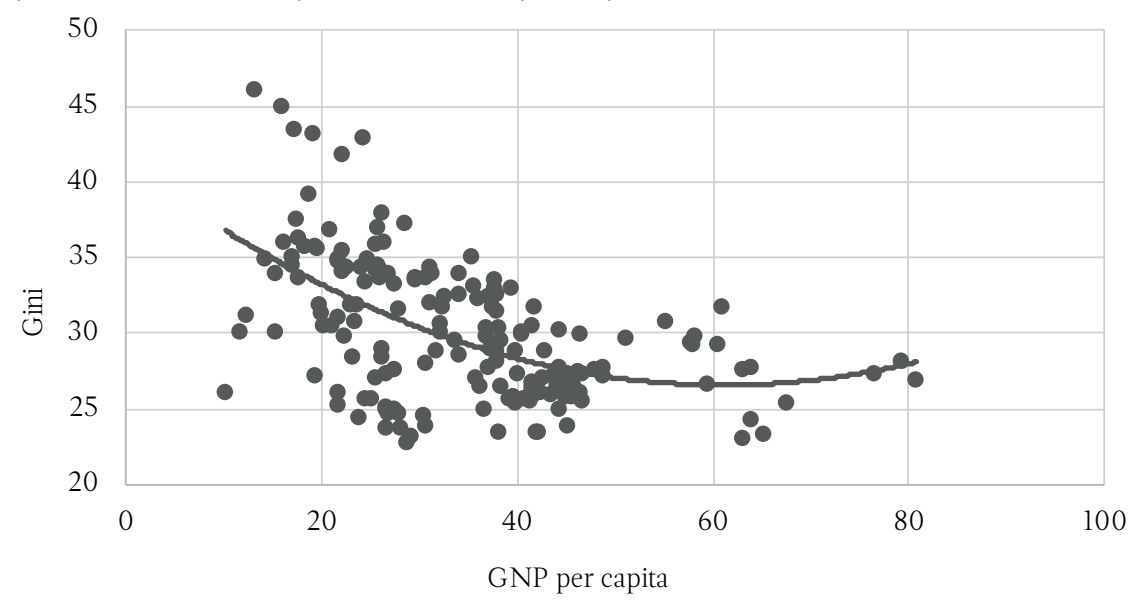

Source: Own preparation. 
